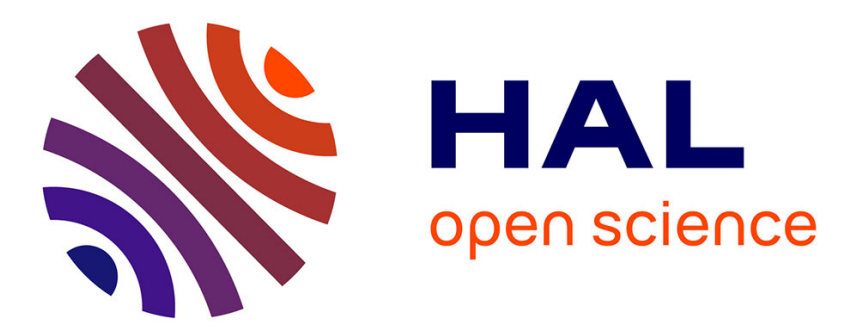

\title{
Discussion of "Economics and Statistical Evaluations of Using Microsoft Excel Solver in Pipe Network Analysis" by I. A. Oke, A. Ismail, S. Lukman, S. O. Ojo, O. O. Adeosun, and M. O. Nwude \\ Dejan Brkić
}

\section{To cite this version:}

Dejan Brkić. Discussion of "Economics and Statistical Evaluations of Using Microsoft Excel Solver in Pipe Network Analysis" by I. A. Oke, A. Ismail, S. Lukman, S. O. Ojo, O. O. Adeosun, and M. O. Nwude. Journal of Pipeline Systems Engineering and Practice, 2018, 9 (3), pp.07018002. 10.1061/(asce)ps.1949-1204.0000319 . hal-01837160

\author{
HAL Id: hal-01837160 \\ https://hal.science/hal-01837160
}

Submitted on 12 Jul 2018

HAL is a multi-disciplinary open access archive for the deposit and dissemination of scientific research documents, whether they are published or not. The documents may come from teaching and research institutions in France or abroad, or from public or private research centers.
L'archive ouverte pluridisciplinaire HAL, est destinée au dépôt et à la diffusion de documents scientifiques de niveau recherche, publiés ou non, émanant des établissements d'enseignement et de recherche français ou étrangers, des laboratoires publics ou privés. 


\section{Journal of Pipeline Systems - Engineering and Practice}

\section{Discussion of "Economics and Statistical Evaluations of Using Microsoft Excel Solver in Pipe Network Analysis" by I.A. Oke; A. Ismail; S. Lukman; S.O. Ojo; O.O. Adeosun; and M.O. Nwude, J. Pipeline Syst. Eng. Pract. 06016002; doi. \\ 10.1061/(ASCE)PS.1949-1204.0000240 \\ --Manuscript Draft--}

Manuscript Number:

Full Title:

Manuscript Region of Origin:

Article Type:

Corresponding Author:

Corresponding Author E-Mail:

Order of Authors:

\section{Additional Information:}

Question

The flat fee for including color figures in print is $\$ 800$, regardless of the number of color figures. There is no fee for online only color figures. If you decide to not print figures in color, please ensure that the color figures will also make sense when printed in black-and-white, and remove any reference to color in the text. Only one file is accepted for each figure. Do you intend to pay to include color figures in print? If yes, please indicate which figures in the comments box.

Authors are required to attain permission to re-use content, figures, tables, charts, maps, and photographs for which the authors do not hold copyright. Figures created by the authors but previously published under copyright elsewhere may require permission. For more information see

http://ascelibrary.org/doi/abs/10.1061/978 0784479018.ch03. All permissions must be uploaded as a permission file in PDF format. Are there any required permissions that have not yet been secured? If yes, please explain in the comment box.

If there is anything else you wish to communicate to the editor of the journal, please do so in this box.

\section{PSENG-493R2}

Discussion of "Economics and Statistical Evaluations of Using Microsoft Excel Solver in Pipe Network Analysis" by I.A. Oke; A. Ismail; S. Lukman; S.O. Ojo; O.O. Adeosun; and M.O. Nwude, J. Pipeline Syst. Eng. Pract. 06016002; doi. 10.1061/(ASCE)PS.1949-1204.0000240

ITALY

Discussion

Dejan Brkic

European Commission

Ispra, Varese ITALY

dejanbrkic0611@gmail.com

Dejan Brkic

\section{Response}

No

No 
1 Discussion of "Economics and Statistical Evaluations of Using Microsoft Excel Solver in Pipe

2 Network Analysis" by I.A. Oke; A. Ismail; S. Lukman; S.O. Ojo; O.O. Adeosun; and M.O. Nwude, J.

3 Pipeline Syst. Eng. Pract. 06016002; doi. 10.1061/(ASCE)PS.1949-1204.0000240

Dejan Brkić, PhD, Research Scientific Officer; European Commission, DG Joint Research Centre (JRC),

Directorate C: Energy, Transport and Climate, Unit C3: Energy Security, Distribution and Markets,

Via Enrico Fermi 2749, 21027 Ispra (VA), Italy, dejanbrkic0611@gmail.com, ORCID id: 0000-0002$2502-0601$

Analysis of few pipe networks is shown in the discussed paper where the authors conclude that the distribution of flow in a network of pipes with known topology, fixed pipe lengths and diameters, with the known and constant inputs and outputs assigned to nodes (connection between two pipes)

12 for the chosen flow friction model (e.g. Colebrook's) depends among other on the chosen method

13 for calculation of flow and pressure distribution in looped network of pipes. That conclusion is not

14 sustainable. Also friction factors are used as constant which cannot be recommended.

Hydraulic analysis of the network from Figure 4 of the discussed paper (the network with five pipes and two loops) is repeated in this discussion.

\section{Flow Friction}

In the discussed paper flow friction factor is given with the constant value of $f=0.02$ in examples 1 and 2 , and $\mathrm{f}=0.0242$ in example 3 (Tables 1 and 2 of the discussed paper). It is not acceptable. Flow

21 friction factor is being changed during the calculation between $f=0.02012$ and $f=0.02571$. Flow

22 friction is complex variable usually determined by empirical Colebrook's equation (1) or some of its

23 related approximations (Colebrook 1939; Brkić 2011a, 2012a, 2017):

$24 \quad \frac{1}{\sqrt{\mathrm{f}}}=-2 \cdot \log _{10}\left(\frac{2.51}{\mathrm{R} \cdot \sqrt{\mathrm{f}}}+\frac{\varepsilon}{3.71 \cdot \mathrm{D}}\right)$ 
It is not obligatory to use this equation. Other equations can be used but $f$ for sure cannot be treated as a constant. As the friction factor $f$ is not a constant and even not always in turbulent zone for which Colebrook's equation (1) is only valid, it can be even suggested to use explicit approximation of the Colebrook equation (1a) but which is in addition valid also for laminar, and the transition in between laminar and turbulent zone (Swamee 1993):

$30 f \approx\left\{\left(\frac{64}{R}\right)^{8}+9.5\left[\ln \left(\frac{\varepsilon}{3.7 \cdot \mathrm{D}}+\frac{5.74}{R^{0.9}}\right)-\left(\frac{2500}{R}\right)^{6}\right]^{-16}\right\}^{0.125}$

31 The relation between pressure drop " $\Delta p$ " and flow " $Q$ " through pipe is $\Delta p=r \cdot Q^{2}$ and with the simplification where " $r$ " is with constant value (although it depends on variable " $f$ "), it is similar to Ohm's law for electrical circuits which relates voltage "U" and electrical current "I" through constant thermal resistance " $R_{T}$ " as $U=I \cdot R_{T}$; note that $R$ in Eqs. 1 and 1 a is not thermal resistance but the Reynolds number. With linearization $\mathrm{x}=\mathrm{Q}^{2}$, system of equations for pipe network in form $\Delta \mathrm{p}=\mathrm{r} \cdot \mathrm{x}$ can be solved using non iterative methodology for electrical circuits. Knowing " $x$ " for each pipe, the flow "Q" can be calculated easily. Such simplification would not produce accurate results (Liou 1998; Simpson and Elhay 2011; Brkić 2012b, 2014).

Hydraulic analysis of pipe network with loops - flow distribution through pipes for known inputs and outputs through nodes

The network used for analysis is shown in Figure 1. Pipe length, diameters and node consumption are constants. The first assumed flow pattern through pipes is chosen arbitrarily with only one condition to maintain flow balance in every node (material balance; first Kirchhoff law). The kinematic viscosity of water is prescribed as $\mu=1.0037 \cdot 10^{-6} \mathrm{~m}^{2} / \mathrm{s}$, and absolute roughness of pipes is estimated at $\varepsilon=0.00026 \mathrm{~m}$ (Brkić 2016).

Figure 1. Network with five pipes and two loops (adapted from the discussed paper) 
50 Following the first Kirchhoff's law, system of equations for nodes can be established (2); where $Q_{1-5}$

51 are flows through pipes and will be changed during calculation:

52

$$
\begin{array}{r|r}
Q_{1}-Q_{2}-0.08=0 & A_{\text {node }} \\
0.4-Q_{1}-Q_{3}-Q_{5}=0 & B_{\text {node }} \\
Q_{4}+Q_{5}-0.2=0 & C_{\text {node }} \\
Q_{2}+Q_{3}-Q_{4}-0.12=0 & D_{\text {node }}
\end{array}
$$

53 For two closed paths, following the second Kirchhoff's law, systems of equations for loops can be

54 established (3); where $\Delta \mathrm{p}_{1-5}$ are pressure drops in pipes and their algebraic sum for each closed path

55 in the network has to be approximately zero.

56

$$
\begin{aligned}
& \begin{array}{l}
\Delta p_{1}+\Delta p_{2}-\Delta p_{3}= \\
=\frac{8 \cdot \rho}{\pi^{2}} \cdot\left(\frac{f_{1} \cdot \mathrm{L}_{1} \cdot Q_{1}^{2}}{\mathrm{D}_{1}^{5}}+\frac{f_{2} \cdot \mathrm{L}_{2} \cdot Q_{2}^{2}}{\mathrm{D}_{2}^{5}}-\frac{f_{3} \cdot \mathrm{L}_{3} \cdot Q_{3}^{2}}{\mathrm{D}_{3}^{5}}\right) \approx 0
\end{array} \\
& \Delta p_{3}+\Delta p_{4}-\Delta p_{5}=\quad \quad \quad I_{\text {loop }} \\
& \left.=\frac{8 \cdot \rho}{\pi^{2}} \cdot\left(\frac{f_{3} \cdot \mathrm{L}_{3} \cdot Q_{3}^{2}}{\mathrm{D}_{3}^{5}}+\frac{f_{4} \cdot \mathrm{L}_{4} \cdot Q_{4}^{2}}{\mathrm{D}_{4}^{5}}-\frac{f_{5} \cdot \mathrm{L}_{5} \cdot Q_{5}^{2}}{\mathrm{D}_{5}^{5}}\right) \approx 0\right)
\end{aligned}
$$

First derivative of $\Delta p(Q)$; pressure drop " $\Delta p$ " in function of flow " $Q$ " as variable can be calculated as

58 (4):

59

$F^{\prime}=\frac{\partial(\Delta p)}{\partial Q}=\frac{\partial\left(\frac{8 \cdot \rho \cdot f \cdot \mathrm{L} \cdot Q \cdot|Q|}{\pi^{2} \cdot \mathrm{D}^{5}}\right)}{\partial Q}=\frac{\partial(r \cdot Q \cdot|Q|)}{\partial Q}=\frac{16 \cdot \rho \cdot \lambda \cdot \mathrm{L} \cdot|Q|}{\pi^{2} \cdot \mathrm{D}^{5}}=2 \cdot r \cdot|Q|$

60 Original version of Hardy Cross method (Cross 1936) in matrix form, accelerated version of Hardy

61 Cross method also known as Newton-Raphson method modified by Epp and Fowler (1971) and

62 node-loop method by Wood and Charles (1972) improved by Wood and Rayes (1981) will be used.

63

64

Accelerated Hardy Cross method

65

Matrix of derivatives $\left[\mathrm{F}^{\prime}\right]$ can be established as (5); where on the main diagonal, upper term

66 represent sum of the absolute values of the derivatives from loop I while lower term represents sum 
67 of the absolute values of the derivatives from loop II. Terms $-\left|F_{3}^{\prime}\right|$ are from the pipe 3 because that

68 pipe is common for both loops.

$69 \quad\left[F^{\prime}\right]=\left[\begin{array}{cc}\left|F_{1}^{\prime}\right|+\left|F_{2}^{\prime}\right|+\left|F_{3}^{\prime}\right| & -\left|F_{3}^{\prime}\right| \\ -\left|F_{3}^{\prime}\right| & \left|F_{3}^{\prime}\right|+\left|F_{4}^{\prime}\right|+\left|F_{5}^{\prime}\right|\end{array}\right]$

70 Correction of flow " $\Delta Q$ " will be calculated in each iteration from $\left[F^{\prime}\right] \times[\Delta Q]=[\Delta p]$, where $\left[F^{\prime}\right]$ is from

71 (5), and where $[\Delta p]$ is based on (3). For the presented network it will be (6):

$72\left[\begin{array}{c}\Delta p_{1}+\Delta p_{2}-\Delta p_{3} \\ \Delta p_{3}+\Delta p_{4}-\Delta p_{5}\end{array}\right]=\left[\begin{array}{cc}\left|F_{1}^{\prime}\right|+\left|F_{2}^{\prime}\right|+\left|F_{3}^{\prime}\right| & -\left|F_{3}^{\prime}\right| \\ -\left|F_{3}^{\prime}\right| & \left|F_{3}^{\prime}\right|+\left|F_{4}^{\prime}\right|+\left|F_{5}^{\prime}\right|\end{array}\right] x\left[\begin{array}{c}\Delta Q_{I} \\ \Delta Q_{I I}\end{array}\right]$

$73 \Delta Q_{І}$ and $\Delta Q_{\|}$are correction of flow which will respectfully will receive each pipe in loop I and loop II

74 where pipe 3 common to both loops will receive both correction simultaneously following algebraic

75 rules for that (Corfield et al. 1974; Brkić 2009).

76

Original Hardy Cross method in matrix form

78 The same procedure as for the accelerated Hardy Cross method will be used with only difference

79 that term $-\left|F_{3}^{\prime}\right|$ in matrix (5) will be zero. With this term equalized with zero the convergence

80 toward the balanced solution is much slower.

81

\section{The node-loop method}

83 To avoid calculation of flow " $Q$ " through " $\Delta Q$ ", Wood and Charles (1972) and Wood and Rayes

84 (1981) introduced the node-loop method. Flow $Q$ can be calculated using [Q]=inv[NL]x[V] where

85 matrix [NL] and [V] are defined as (7) and (8) respectively as described in Brkić (2011b, 2016). To

86 preserve linear independency among rows of [NL], one arbitrarily chosen node has to be omitted (in

87 this case node $\mathrm{D})$. 
$\left.88 \quad[N L]=\left[\begin{array}{ccccc}1 & -1 & 0 & 0 & 0 \\ -1 & 0 & -1 & 0 & -1 \\ 0 & 0 & 0 & 1 & 1 \\ F_{1}^{\prime} & F_{2}^{\prime} & -F_{3}^{\prime} & 0 & 0 \\ 0 & 0 & F_{3}^{\prime} & F_{4}^{\prime} & -F_{5}^{\prime}\end{array}\right]\right\} \begin{aligned} & A_{\text {loop }} \\ & B_{\text {loop }} \\ & C_{\text {loop }} \\ & I_{\text {node }} \\ & I I_{\text {node }}\end{aligned}$

$\left.89 \quad[V]=\left[\begin{array}{c}0.08 \\ -0.4 \\ 0.2 \\ -\left(\Delta p_{1}+\Delta p_{2}-\Delta p_{3}\right)+\left(\left|F_{1}^{\prime}\right| \cdot Q_{1}+\left|F_{2}^{\prime}\right| \cdot Q_{2}+\left|F_{3}^{\prime}\right| \cdot Q_{3}\right) \\ -\left(\Delta p_{3}+\Delta p_{4}-\Delta p_{5}\right)+\left(\left|F_{3}^{\prime}\right| \cdot Q_{3}+\left|F_{4}^{\prime}\right| \cdot Q_{4}+\left|F_{5}^{\prime}\right| \cdot Q_{5}\right)\end{array}\right]\right)\left[\begin{array}{c}A_{\text {node-output }} \\ B_{\text {node-input }} \\ C_{\text {node-output }} \\ I_{\text {loop }} \\ I I_{\text {loop }}\end{array}\right.$

90 In [V], first three rows are with constant values during whole calculation (in every iteration).

91

92 Results

93 Tree methods were used for calculation, the original Hardy Cross, the accelerated Hardy Cross

94 (Newton Raphson) and the node-loop. The final solution is reached after approximately 9 iterations

95 using the accelerated Hardy Cross (Newton Raphson) and the node-loop and after approximately 28

96 iterations using original Hardy Cross method. The final results are identical and they are listed in

97 Table 1:

98

99

Table 1. Information about the network, the flows obtained, pressure drops and related head losses

100

101 All calculations were performed in Microsoft Excel.

102

103 Conclusion

104 Calculation with flow friction factor treated as constant cannot be recommended. Also using the

105 chosen flow friction model (e.g. Colebrook's), final flow distribution does not depend on the chosen

106 method (e.g. Hardy Cross, the node-loop method, etc.) for one defined network with known and 
107 constant pipe diameters, lengths and roughness of inner pipe surface and with constant consumptions and inputs assigned to nodes (Gay and Middleton 1971).

109

110 Supplementary material:

111 Complete calculation using the node-loop method extracted from MS Excel is provided.

112

\section{Notation}

114 The following symbols are used in this discussion:

$115 \mathrm{R}-$ Reynolds number (dimensionless)

$116 \varepsilon / D-$ Relative roughness of inner pipe surface (dimensionless)

$117 \quad f-$ Darcy (Moody) flow friction factor (dimensionless)

$118 \mathrm{Q}$ - volumetric flow $\left(\mathrm{m}^{3} / \mathrm{sec}\right)$

$119 \Delta p-$ pressure drop $(\mathrm{Pa})$

$120 \rho$-water density $\left(\mathrm{kg} / \mathrm{m}^{3}\right)$

$121 \quad \mathrm{~L}$ - length pf pipe $(\mathrm{m})$

$122 \quad$ D - diameter of pipe $(\mathrm{m})$

$123 \pi$-Ludolph number, $\pi \approx 3.1415$

124

125 Disclaimer: Neither the European Commission nor any person acting on behalf of it is responsible for

126 the use which might be made of this publication.

128 References:

129 Brkić, D. (2009). "An improvement of Hardy Cross method applied on looped spatial natural gas

130 distribution networks.", Appl. Energ. 86(7-8), 1290-1300. doi:10.1016/j.apenergy.2008.10.005

131 Brkić, D. (2011a). "Review of explicit approximations to the Colebrook relation for flow friction." J.

132 Petrol. Sci. Eng. 77(1), 34-48. doi. 10.1016/j.petrol.2011.02.006 
133 Brkić, D. (2011b). "Iterative methods for looped network pipeline calculation.", Water. Resour.

Manag. 25(12), 2951-2987. doi:10.1007/s11269-011-9784-3

Brkić, D. (2012a). "Determining friction factors in turbulent pipe flow." Chem. Eng. (New York) 119(3), 34-39. From: www.chemengonline.com/determining-friction-factors-in-turbulent-pipeflow/?printmode=1

Brkić, D. (2012b). “Discussion of 'Jacobian matrix for solving water distribution system equations with the Darcy-Weisbach head-loss model' by Angus Simpson and Sylvan Elhay." J. Hydraul. Eng., 138(11), 1000-1001. doi:10.1061/(ASCE)HY.1943-7900.0000529

Brkić, D. (2014). "Discussion of 'Method to cope with zero flows in Newton solvers for water 7900.0000769

Brkić, D. (2016). "Spreadsheet-based pipe networks analysis for teaching and learning purpose.",

146 Spreadsheets in Education (eJSiE), 9(2), Article 4. http://epublications.bond.edu.au/ejsie/vol9/iss2/4

147 Brkić, D. (2017). “Discussion of 'Exact analytical solutions of the Colebrook-White equation' by Yozo Mikata and Walter S. Walczak." J. Hydraul. Eng. 143(9). doi:10.1061/(ASCE)HY.1943-7900.0001341 Colebrook, C.F. (1939). "Turbulent flow in pipes with particular reference to the transition region between the smooth and rough pipe laws." J. Inst. Civil. Eng. (London) 11(4), 133-156. doi. 10.1680/ijoti.1939.13150 Corfield, G., Hunt, B.E., Ott, R.J., Binder, G.P., and Vandaveer, F.E. (1974). “Distribution design for

153 increased demand," 63-83 [chapter 9]. In: Segeler, C.G., editor. Gas engineers handbook, Industrial 154 Press, New York.

155 Cross, H. (1936). "Analysis of flow in networks of conduits or conductors.", Urbana Champaign Univ.

156 III. Bull. 286; Eng. Exp. Station, 34(22), 3-29. http://hdl.handle.net/2142/4433

157 Epp, R, and Fowler, A.G. (1970). "Efficient code for steady flows in networks." J. Hydraul. Div. ASCE, 158 96(HY1), 43-56. 
159 Gay, B., and Middleton, P. (1971). "The solution of pipe network problems." Chem. Eng. Sci., 26(1),

160 109-123. doi:10.1016/0009-2509(71)86084-0

161 Liou, C. (1998). "Limitations and proper use of the Hazen-Williams equation." J. Hydraul. Eng.,

162 124(9), 951-954. doi. 10.1061/(ASCE)0733-9429(1998)124:9(951)

163 Simpson, A. and Elhay, S. (2011). "Jacobian matrix for solving water distribution system equations

164 with the Darcy-Weisbach head-loss model." J. Hydraul. Eng. 137 (6), 696-700.,

165 doi:10.1061/(ASCE)HY.1943-7900.0000341

166 Swamee, P.K.(1993). “Design of a submarine oil pipeline.” J. Transp. Engrg., ASCE, 119(1), 159-170.,

167 doi:10.1061/(ASCE)0733-947X(1993)119:1(159)

168 Wood, D., and Charles, C. (1972). "Hydraulic network analysis using linear theory.", J. Hydraul. Div.

169 ASCE, 98(HY7), 1157-1179.

170 Wood, D.J., and Rayes, A.G. (1981). "Reliability of algorithms for pipe network analysis.", J. Hydraul.

171 Div. ASCE, 107(HY10), 1145-1161. 
Table 1. Information about the network, the flows obtained, pressure drops and related head losses

\begin{tabular}{|c|c|c|c|c|c|c|c|}
\hline \multicolumn{3}{|l|}{ Pipe } & \multirow[b]{2}{*}{ r } & \multirow[b]{2}{*}{ Flow $\left(\mathrm{m}^{3} \cdot \mathrm{s}^{-1}\right)$} & \multirow[b]{2}{*}{ Pressure drop $\Delta \mathrm{p}(\mathrm{Pa})$} & \multirow[b]{2}{*}{$K=r \cdot \rho^{-1} \cdot g^{-1}$} & \multirow[b]{2}{*}{$\begin{array}{l}\text { Head loss } H(m) \\
H=\Delta p \cdot \rho^{-1} \cdot g^{-1}\end{array}$} \\
\hline Number & $\begin{array}{c}\text { Diameter } \\
\mathrm{D}(\mathrm{m})\end{array}$ & $\begin{array}{l}\text { Length L } \\
(\mathrm{m})\end{array}$ & & & & & \\
\hline 1 & 0.25 & 1000 & 16741273.11 & 0.170123 & 484523.91 & 1706.55 & 49.39 \\
\hline 2 & 0.20 & 1500 & 81276026.10 & 0.090123 & 660138.41 & 8285.01 & 67.29 \\
\hline 3 & 0.15 & 1800 & 442404818.12 & 0.050866 & 1144662.32 & 45097.33 & 116.68 \\
\hline 4 & 0.10 & 1000 & 2083940584.61 & 0.020989 & 918078.81 & 212430.23 & 93.58 \\
\hline 5 & 0.20 & 1200 & 64370456.71 & 0.179011 & 2062741.10 & 6561.71 & 210.26 \\
\hline
\end{tabular}




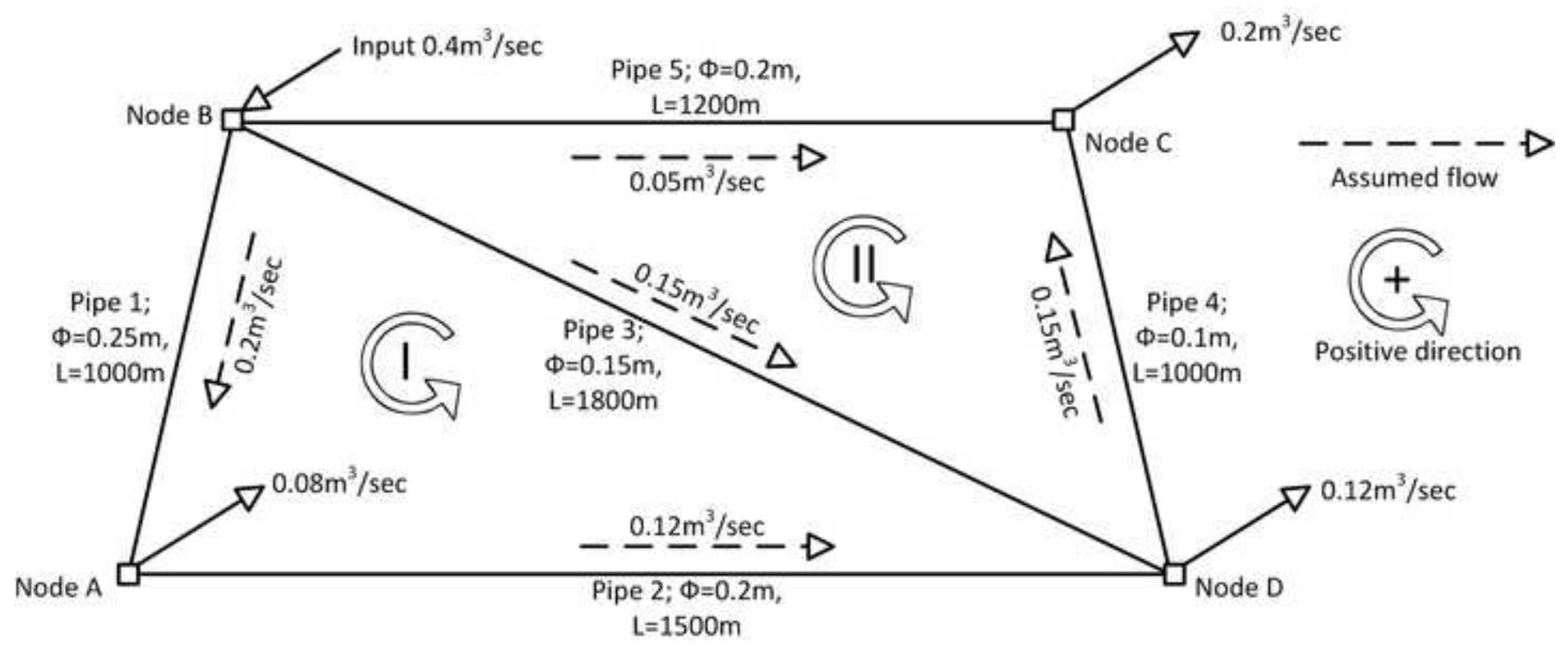


Figure Captions List DB

Figure caption list

Figure 1. Network with five pipes and two loops (adapted from the discussed paper) 
El. Annex
\[ \begin{array}{l}\text { Click here to access/download } \\ \text { Node-Loop method Data File }\end{array} \]
Noded Dodf

El. Annex
\[ \begin{array}{l}\text { Click here to access/download } \\ \text { Node-Loop method Data File }\end{array} \]
Noded Dodf

El. Annex
\[ \begin{array}{l}\text { Click here to access/download } \\ \text { Node-Loop method Data Dile }\end{array} \]
Nodf

(n)

Node-Loop method DB.pdf 


\section{ASCE Authorship, Originality, and Copyright Transfer Agreement} Publication Title: Journal of Pipeline Systems Engineering and Practice

Manuscript Title: Discussion of "Economics and Statistical Evaluations of Using Microsoft Excel Solver in Pipe Network Analysis"

Author(s) - Names, postal addresses, and e-mail addresses of all authors

Dejan Brkić, PhD, Research Scientific Officer; European Commission, DG Joint Research Centre (JRC)

Directorate C: Energy, Transport and Climate, Unit C3: Energy Security, Distribution and Markets,

Via Enrico Fermi 2749, 21027 Ispra (VA), Italy, dejanbrkic0611@gmail.com

\section{Authorship Responsibility}

To protect the integrity of authorship, only people who have significantly contributed to the research or project and manuscript preparation shall be listed as coauthors. The corresponding author attests to the fact that anyone named as a coauthor has seen the final version of the manuscript and has agreed to its submission for publication. Deceased persons who meet the criteria for coauthorship shall be included, with a footnote reporting date of death. No fictitious name shall be given as an author or coauthor. An author who submits a manuscript for publication accepts responsibility for having properly included all, and only, qualified coauthors.

I, the corresponding author, confirm that the authors listed on the manuscript are aware of their authorship status and qualify to be authors on the manuscript according to the guidelines above.

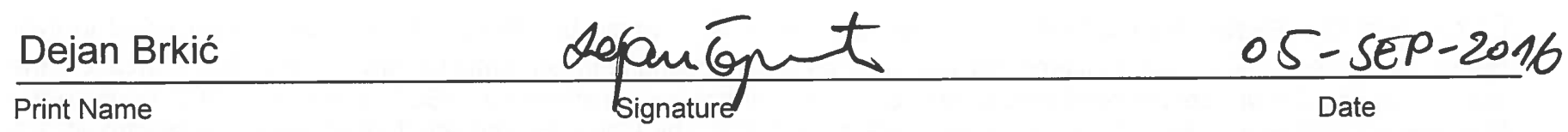

\section{Originality of Content}

ASCE respects the copyright ownership of other publishers. ASCE requires authors to obtain permission from the copyright holder to reproduce any material that (1) they did not create themselves and/or (2) has been previously published, to include the authors' own work for which copyright was transferred to an entity other than ASCE. Each author has a responsibility to identify materials that require permission by including a citation in the figure or table caption or in extracted text. Materials re-used from an open access repository or in the public domain must still include a citation and URL, if applicable. At the time of submission, authors must provide verification that the copyright owner will permit re-use by a commercial publisher in print and electronic forms with worldwide distribution. For Conference Proceeding manuscripts submitted through the ASCE online submission system, authors are asked to verify that they have permission to re-use content where applicable. Written permissions are not required at submission but must be provided to ASCE if requested. Regardless of acceptance, no manuscript or part of a manuscript will be published by ASCE without proper verification of all necessary permissions to re-use. ASCE accepts no responsibility for verifying permissions provided by the author. Any breach of copyright will result in retraction of the published manuscript.

I, the corresponding author, confirm that all of the content, figures (drawings, charts, photographs, etc.), and tables in the submitted work are either original work created by the authors listed on the manuscript or work for which permission to reuse has been obtained from the creator. For any figures, tables, or text blocks exceeding 100 words from a journal article or 500 words from a book, written permission from the copyright holder has been obtained and supplied with the submission.

$\frac{\text { Dejan Brkić }}{\text { Print name }}$

\section{Copyright Transfer}

ASCE requires that authors or their agents assign copyright to ASCE for all original content published by ASCE. The author(s) warrant(s) that the above-cited manuscript is the original work of the author(s) and has never been published in its present form. 
The undersigned, with the consent of all authors, hereby transfers, to the extent that there is copyright to be transferred, the exclusive copyright interest in the above-cited manuscript (subsequently called the "work") in this and all subsequent editions of the work (to include closures and errata), and in derivatives, translations, or ancillaries, in English and in foreign translations, in all formats and media of expression now known or later developed, including electronic, to the American Society of Civil Engineers subject to the following:

- The undersigned author and all coauthors retain the right to revise, adapt, prepare derivative works, present orally, or distribute the work, provided that all such use is for the personal noncommercial benefit of the author(s) and is consistent with any prior contractual agreement between the undersigned and/or coauthors and their employer(s).

- No proprietary right other than copyright is claimed by ASCE.

- If the manuscript is not accepted for publication by ASCE or is withdrawn by the author prior to publication (online or in print), or if the author opts for open-access publishing during production (journals only), this transfer will be null and void.

- Authors may post a PDF of the ASCE-published version of their work on their employers' Intranet with password protection. The following statement must appear with the work: "This material may be downloaded for personal use only. Any other use requires prior permission of the American Society of Civil Engineers."

- Authors may post the final draft of their work on open, unrestricted Internet sites or deposit it in an institutional repository when the draft contains a link to the published version at www.ascelibrary.org. "Final draft" means the version submitted to ASCE after peer review and prior to copyediting or other ASCE production activities; it does not include the copyedited version, the page proof, a PDF, or full-text HTML of the published version.

Exceptions to the Copyright Transfer policy exist in the following circumstances. Check the appropriate box below to indicate whether you are claiming an exception:

U.S. GOVERNMENT EMPLOYEES: Work prepared by U.S. Government employees in their official capacities is not subject to copyright in the United States. Such authors must place their work in the public domain, meaning that it can be freely copied, republished, or redistributed. In order for the work to be placed in the public domain, ALL AUTHORS must be official U.S. Government employees. If at least one author is not a U.S. Government employee, copyright must be transferred to ASCE by that author.

CROWN GOVERNMENT COPYRIGHT: Whereby a work is prepared by officers of the Crown Government in their official capacities, the Crown Government reserves its own copyright under national law. If ALL AUTHORS on the manuscript are Crown Government employees, copyright cannot be transferred to ASCE; however, ASCE is given the following nonexclusive rights: (1) to use, print, and/or publish in any language and any format, print and electronic, the above-mentioned work or any part thereof, provided that the name of the author and the Crown Government affiliation is clearly indicated; (2) to grant the same rights to others to print or publish the work; and (3) to collect royalty fees. ALL AUTHORS must be official Crown Government employees in order to claim this exemption in its entirety. If at least one author is not a Crown Government employee, copyright must be transferred to ASCE by that author.

WORK-FOR-HIRE: Privately employed authors who have prepared works in their official capacity as employees must also transfer copyright to ASCE; however, their employer retains the rights to revise, adapt, prepare derivative works, publish, reprint, reproduce, and distribute the work provided that such use is for the promotion of its business enterprise and does not imply the endorsement of ASCE. In this instance, an authorized agent from the authors' employer must sign the form below.

U.S. GOVERNMENT CONTRACTORS: Work prepared by authors under a contract for the U.S. Government (e.g., U.S. Government labs) may or may not be subject to copyright transfer. Authors must refer to their contractor agreement. For works that qualify as U.S. Government works by a contractor, ASCE acknowledges that the U.S. Government retains a nonexclusive, paid-up, irrevocable, worldwide license to publish or reproduce this work for U.S. Government purposes only. This policy DOES NOT apply to work created with U.S. Government grants.

I, the corresponding author, acting with consent of all authors listed on the manuscript, hereby transfer copyright or claim exemption to transfer copyright of the work as indicated above to the American Society of Civil Engineers.

\section{Dejan Brkić}

Print Name of Author or Agent

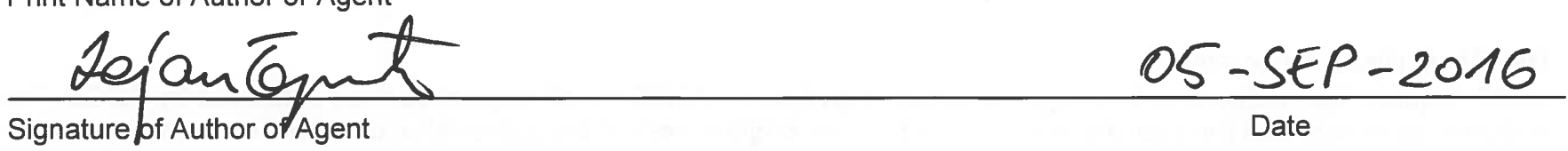

More information regarding the policies of ASCE can be found at http://www.asce.org/authorsandeditors 


\section{Dear Editor,}

The required file is now attached as "supplemental material". It has been part of submission since the first version of manuscript.

Best regards,

Dejan Brkić 